\title{
A New Opportunity
}

\section{Catherine J. Tompkins ${ }^{1}$}

Published online: 14 May 2020

(C) Springer Science+Business Media, LLC, part of Springer Nature 2020

It is a privilege to be selected as the Editor of Ageing International. I inherited a journal that is ready to be launched to the next level, due to the leadership of Dr. Sue Levkoff and Dr. Hongtu Chen. I want to thank them for their attention and dedication to the journal. I am thankful to my current leadership team Sonya Sonneman and Allison DeVille, and the good work of the journal's editorial board. We continue to have authors and reviewers from across the globe sharing their knowledge and expertise. Ageing International is dedicated to exploring and examining issues related to improving the lives of older adults and their families. The journal continues to provide an intellectual forum for communicating common concerns, exchanging discoveries and analyses in scientific research, and crystallizing significant social and health policy issues.

I remain committed to the journal and its focus on providing evidence that supports improving the lives of older adults, their caregivers, and families. The multidisciplinary approach is a framework that I think is important to disseminate, while at the same time, continuing to compare and contrast the disciplinary approaches to policy and practice interventions.

The world is changing. Life after COVID-19 will require new innovative ways to provide support and care to the older members of our world. Developing and examining interventions and trainings that prepare formal and family caregivers to provide daily, superior care to older adults, as well as quality of care in a crisis is imperative. We need to disseminate the evidence-based work provided by our front-line workers in long-term care facilities and home health care, so that the value of what they do is recognized and respected, creating policy changes.

Special issues are one way to address complexity. We are living in a complex time, so we welcome ideas for special issues that address post COVID-19 care for older adults, their caregivers and family members. Brief pieces that analyze Post COVID-19 data will be seen as a priority in the coming months. I look forward to manuscripts that

Catherine J. Tompkins

ctompkin@gmu.edu

1 College of Health and Human Services, George Mason University, 4400 University Drive, MS

1F8, Fairfax, VA, USA 
lead to the greatest post COVID-19 discoveries for the most valued members of our society - older adults.

A quality journal is a shared enterprise. I hope to provide leadership to the enterprise, but it is your continuing support that will move the journal forward and flourishing. I welcome your contributions, questions, and suggestions.

Catherine J. Tompkins is Associate Dean for Faculty Affairs and Professor in the College of Health and Human Services at George MasonUniversity. She has extensive experience working on community-based projects related to older adults and their caregivers, and has been an establishedresearcher at George Mason University for more than fifteen years. The projects she has worked on have utilized both qualitative and quantitative methodsand focus on dementia caregiving and kinship caregiving. Dr. Tompkins is a John A. Hartford Geriatric Scholar in Social Work which allows her to beamong a strong group of national gerontological social work researchers. For a complete listing of Cathy's work, please go to: https:// orcid.org/0000-0002-0476-9007. 